\title{
Modified ultrafast thermometer UFT-M and temperature measurements during Physics of Stratocumulus Top (POST)
}

\author{
W. Kumala ${ }^{1}$, K. E. Haman ${ }^{1}$, M. K. Kopec ${ }^{1}$, D. Khelif ${ }^{2}$, and S. P. Malinowski ${ }^{1}$ \\ ${ }^{1}$ Institute of Geophysics, Faculty of Physics, University of Warsaw, Warsaw, Poland \\ ${ }^{2}$ University of California Irvine, Irvine, CA, USA
}

Correspondence to: S. P. Malinowski (malina@fuw.edu.pl)

Received: 6 November 2012 - Published in Atmos. Meas. Tech. Discuss.: 22 February 2013

Revised: 27 June 2013 - Accepted: 8 July 2013 - Published: 14 August 2013

\begin{abstract}
A modified UFT-M version of the ultrafast airborne thermometer UFT, aimed at in-cloud temperature measurements, was designed for the Physics of Stratocumulus Top (POST) field campaign. Improvements in its construction resulted in the sensor's increased reliability, which provided valuable measurements in 15 of the 17 flights. Oversampling the data allowed for the effective correction of the artefacts resulting from the interference with electromagnetic transmissions from on-board avionic systems and the thermal noise resulting from the sensor construction. The UFT$M$ records, when averaged to the 1.4 and $55 \mathrm{~m}$ resolutions, compared to the similar records of a thermometer in a Rosemount housing, indicate that the housing distorts even lowresolution airborne temperature measurements. Data collected with the UFT-M during the course of POST characterise the thermal structure of stratocumulus and capping inversion with the maximum resolution of $\sim 1 \mathrm{~cm}$. In this paper, examples of UFT-M records are presented and discussed.
\end{abstract}

\section{Introduction}

Physics of Stratocumulus Top (POST) was a research campaign aimed at the airborne investigation of marine stratocumulus clouds and capping inversion. In June and July 2008, a research aircraft, a turbo-prop CIRPAS (Center for Interdisciplinary Remotely-Piloted Aircraft Studies) Twin Otter, equipped with high-resolution instrumentation used to measure thermodynamic, microphysical and dynamic properties of clouds, performed 17 research flights over the Pacific Ocean in the area $\sim 125 \mathrm{~km}$ west of Monterey Bay, California. This area is well known from persistent presence of marine stratocumulus fields capped by a strong inversion due to large-scale subsidence in high-pressure systems. Many earlier campaigns aimed at airborne measurements of stratocumulus properties were performed in Western Pacific along the California coast (see e.g. overview in Wood , 2012). A description of the flight strategy during the POST campaign and a summary of the flights can be found in previous studies (Gerber et al., 2010; Carman et al., 2012; Gerber et al., 2013) and in the POST database held by the NCAR's (National Center for Atmospheric Research) EOL (Earth Observing Laboratory) at http://www. eol.ucar.edu/projects/post/. Of key interest was investigating the interactions among turbulence, thermodynamics and microphysics, which were assessed to improve the understanding of the entrainment of free tropospheric air into stratocumulus clouds and the subsequent mixing processes. The scientific importance of these interactions has been underlined in recent reviews (Bodenschatz et al., 2010; Siebert et al., 2010; Devenish et al., 2012). The main part of each flight (so called "pod", see Fig. 1) consisted of porpoising manoeuvres of an amplitude of $\sim 200 \mathrm{~m}$. These manoeuvres involved ascents from the cloud top region across the capping inversion to the free troposphere and subsequent descents into the cloud top. Additionally, in each pod three horizontal segments: above the sea surface, at the cloud base and close to the cloud top were taken in order estimate turbulent fluxes. A typical flight consisted of three pods and two vertical soundings.

The present study focuses on the description and performance of a specially designed version of the ultrafast thermometer (UFT) (Haman et al., 1997, 2001), which was one of the key instruments used in the POST field campaign and 

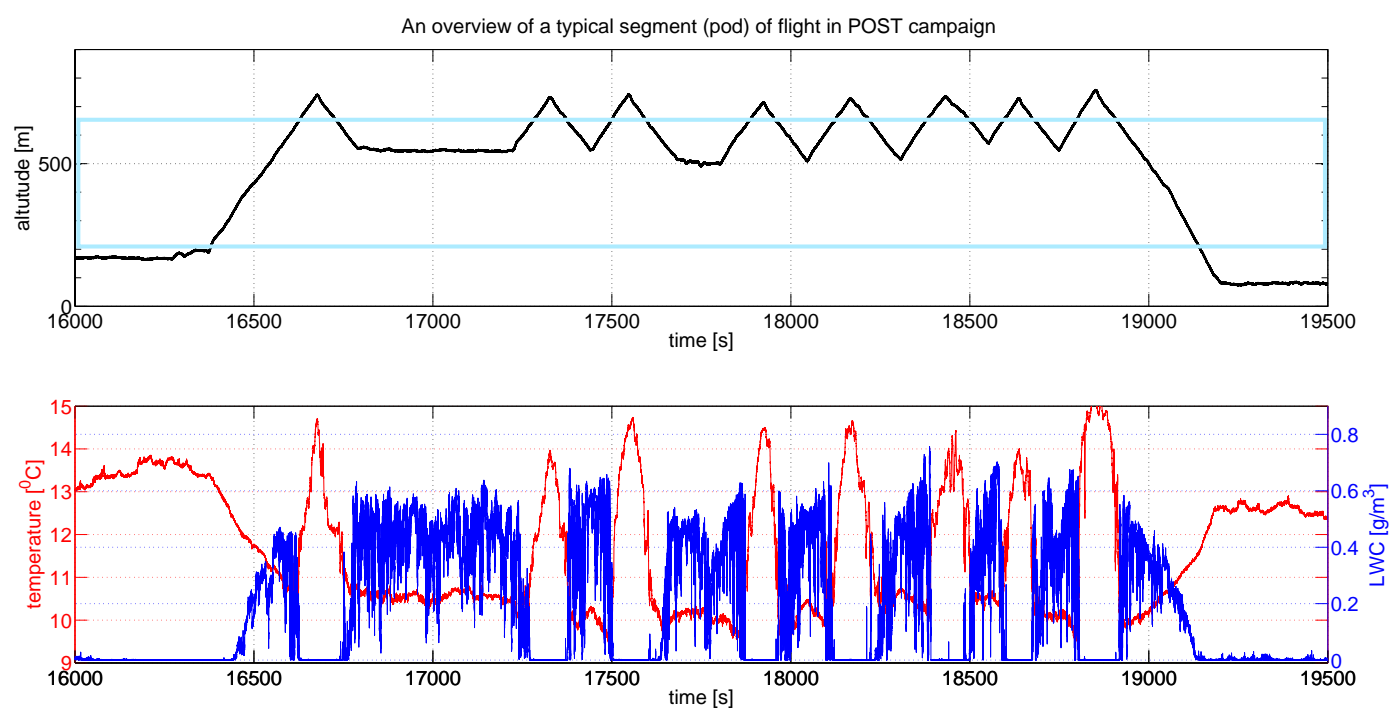

Fig. 1. An illustration of flight strategy adopted for the POST research campaign. In the upper panel flight altitude (black) in the course of a single flight segment called "pod" is plotted, the blue rectangle marks the cloud layer. The lower panel shows corresponding temperature and liquid water content.

may be used in future campaigns that involve airborne investigations of small-scale features of warm clouds. Highresolution temperature measurements are needed to characterise filaments formed in the course of mixing of clouds with the environmental air. They allow to distinguish volumes undergoing active mixing from regions already mixed, characterise homogeneous and inhomogeneous mixing (see discussion in Devenish et al., 2012 and references therein), investigate a relative importance of radiative vs. evaporative cooling in clouds (see e.g. Wood , 2012), and seek for effects of evaporative cooling at the interfaces between cloudy and clear air (Malinowski et al., 2008). It can be also used, together with the other airborne data to characterise properties of different cloud layers and regions (see e.g. Haman et al., 2007; Malinowski et al., 2013). Last, but not least, high-frequency temperature measurements can be used, together with the appropriate vertical velocity data in sensible heat flux estimates from slowly flying aircraft (like in Metzger et al., 2012).

Construction of UFT-M follows a novel airborne thermometer for in-cloud measurements (Haman, 1992). The sensing element of Haman's device (i.e. a $\sim 50 \mu$ m thick thermocouple) was protected from getting wet in the clouds by a specially designed rod. Both, the sensing element and the rod, were placed on a rotatable vane that adapted to the local flow. The unique design was aimed to minimise the unwanted influences of the housing, which typically affect temperature measurements in the following ways:

- aerodynamic effects (Friehe and Khelif, 1992; Mayer et al., 2009);

- thermal inertia of housing (Friehe and Khelif, 1992; Inverarity, 2000); and
- cloud droplets wetting the housing (Lawson and Cooper, 1990; Eastin et al., 2002; Sinkevich and Lawson, 2005; Wang and Geerts, 2009).

During the development process, a moderate-response thermocouple was replaced with a very fine cold wire, which was previously used to measure fast temperature fluctuations in the convective surface layer (Malinowski and Leclerc, 1994). The new sensor, denoted UFT, was described in a previous study of Haman et al. (1997). Its prototype version, mounted on a slowly flying powered glider, allowed for the first airborne temperature measurements in clouds with a resolution on the order of $1 \mathrm{~cm}$ (Haman and Malinowski, 1996). The UFT provided insight into the intriguing smallscale thermal structure of turbulent clouds. Further development resulted in a variety of UFTs that were designed for specific airborne platforms and applications (Haman et al., 2001; Siebert et al., 2003). In particular, the UFT-F (final $\mathrm{F}$ for fast) version of the sensor, which was designed for platforms that make measurements at true air speeds of 50$110 \mathrm{~m} \mathrm{~s}^{-1}$, was used on turbo-prop research aircraft in multiple field campaigns.

While providing unprecedented resolution, the UFTs suffered from drawbacks and were incompatible with the equipment of multiple research aircrafts. Vibrations in flight often led to the deterioration and failure of sensing elements. The UFT's high-frequency output signals were subject to electromagnetic interferences with avionic systems. Specifically, the temperature signal was often affected by interference from a cable that ran between the sensing wire and the amplifier. Additionally, the amplified analogue signal was subject to high-frequency interferences on the signal cables that connected the amplifiers to the dedicated data acquisition 
systems in the cabin. Small imperfections in the shielding or even minimal displacements of the cables from their optimal locations led to artefacts in the recorded signals. For typical low- and moderate-response instruments, this effect is not visible due to signal conditioning and low-pass filtering that occurs prior to recording data. However, the response from the UFT exceeded the capabilities of aircraft data acquisition systems, which required the use of special units and signal conditioning at much higher frequencies. In effect, the overall reliability of UFT sensors often appeared unsatisfactory, which limited their use. In many field campaigns, useful data were available from only $10-20 \%$ of research flights.

To overcome these deficiencies, an improved version of the UFT-F thermometer, UFT-M ( $M$ for modified), was developed. UFT-M proved to be much more reliable than the original UFT-F, providing valuable results from 15 of the 17 research flights that took place during the POST campaign. UFT-M allowed for the collection of very high-resolution (maximum $\sim 1 \mathrm{~cm}$ resolution) records of the thermal structure of stratocumulus clouds and capping inversion. These records, accompanied by high-resolution records of liquid water content (LWC, $5.5 \mathrm{~cm}$ maximum resolution), humidity (55 cm maximum resolution) and 3 components of velocity fluctuations ( $\sim 1.4 \mathrm{~m}$ resolution) from closely collocated instruments, as well as standard-resolution $(\sim 55 \mathrm{~m})$ measurements of microphysics and radiation, were collected over the course of approximately 900 penetrations through a stratocumulus top and led to a unique data set that characterised the interface between the stratocumulus-topped boundary layer and the free troposphere.

In this paper, we describe the UFT-M sensor construction and improvements with respect to previous versions (Sect. 2), the data collection procedure (Sect. 3) and the UFT-M performance during POST (Sect. 3.2) compared to the performance of the temperature sensor in Rosemount housing and present examples of measurements performed with the instrument (Sect. 4).

\section{Description of the UFT-M thermometer}

\subsection{Sensor construction}

The sensing element in all of the thermometers in the UFT family is platinum-coated tungsten resistive wire that is $2.5 \mu \mathrm{m}$ thick and $5 \mathrm{~mm}$ long and has $\sim 50 \Omega$ resistance at room temperature. The small diameter of the sensor results in low thermal inertia and negligible radiative effects, while the large length-to-diameter ratio allows negligible heat transport from the supports (Haman et al., 1997). The sensing wire is positioned $6.5 \mathrm{~mm}$ behind a shielding rod, thus protecting the sensor against droplet impact and moisture. Unfortunately, pressure fluctuations in the eddies shedding from the rod cause temperature fluctuations (i.e. aerodynamic thermal noise) of an amplitude that increases roughly with the square of the true airspeed (TAS).

The design of the rod differs in various versions of UFT. In UFT-F, the rod is aerodynamically shaped and has $12 \mathrm{~mm}-$ long and $0.35 \mathrm{~mm}$-wide slots on its sides, which are connected by means of a pressure duct to the Venturi nozzle that is exposed to the airflow. A pressure deficit from the nozzle sucks off the surface layer from the rod, thus reducing pressure and temperature fluctuations in the wake and removing water collected on the shield. Nylon string $(0.25 \mathrm{~mm}$ diameter), located $3 \mathrm{~mm}$ ahead of the rod, also improves the effectiveness of the shield.

The sensor and protecting rod are mounted on a rotatable vane that adapts to the local airflow. Sketches and photographs of UFT-F thermometers as well as an experimental analysis of temperature fluctuations in the wake can be found in a previous study (Haman et al., 2001). Numerical simulations of the flow around the rod, vortex shedding effects and droplet trajectories have also been previously examined (Rosa et al., 2005). A concise description of the sensor can be found in Bange et al. (2013).

The current version of the UFT-M sensor, pictured in Fig. 2, has a similar geometry to the UFT-F. The difference is that the slots in the protecting rods are elongated to $17 \mathrm{~mm}$. The slots are elongated such that two independent sensing elements can be placed behind the rod, thus ensuring redundancy.

Other modifications introduced to minimise the deficiencies of the UFT-F include the following:

- a redesigned miniaturised amplifier circuit, placed close to the sensing elements to minimise electromagnetic interferences with avionics; and

- a redesigned vane with an increased stiffness and with improved bearings on the axis to reduce vibrations.

The sensing wires are soldered to the tips of the Tefloncoated copper connectors placed inside stiff stainless steel tubes. The middle connector, common to both sensing wires, is the common ground. Two independent pre-amplifiers collect signals from the outer connectors. The current in the sensing wires is reduced to $2 \mathrm{~mA}$ to minimise resistive heating.

An electronic circuit, ensuring a 68-fold amplification of the signals, a frequency response up to $20 \mathrm{kHz}$ and output noise less than $1 \mathrm{mV}$ peak to peak, is surface-mounted on a specially designed printed board that is small enough to be hidden inside the vane. The whole circuit, except for the sensing wires, is screened. The printed board is inside the envelope of a copper foil, and connectors to the sensing wires are inside the stainless steel tubes, which are structural elements of the vane and support the sensing wires. Screening is important, as a weak signal from the sensor is easily affected by electromagnetic disturbances (e.g. from aircraft radar, radio and/or avionic systems). 


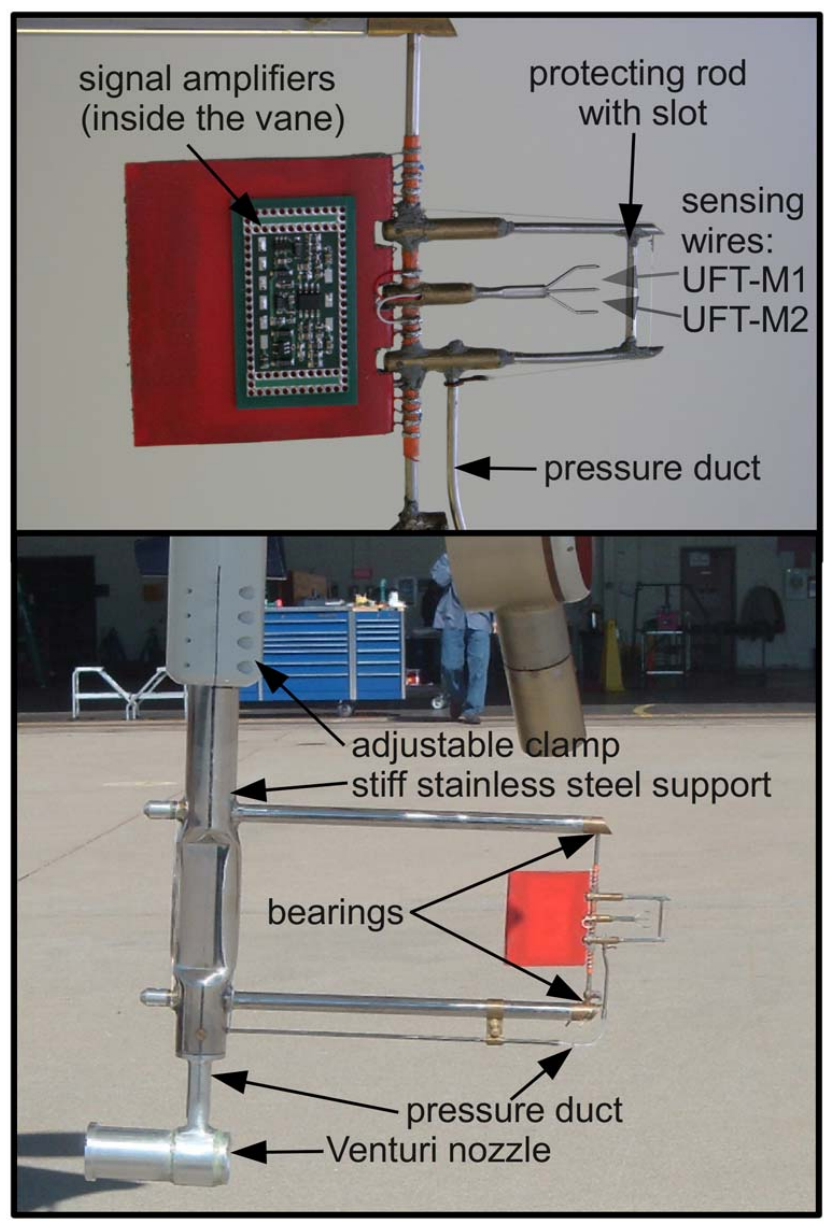

Fig. 2. The UFT-M as used in POST. Upper panel: the sensor, sensing wires 1 and 2 are referred as UFT-M1 and UFT-M2. A printed circuit with the electronics, here exposed, is screened and hidden inside the red tail of the vane. Lower panel: the sensor support and mounting details.

The sensitivity of the amplified signal is $\sim 25 \mathrm{mV} \mathrm{K}^{-1}$, and the thermal drift is less than $0.25 \mathrm{mV} \mathrm{K}^{-1}$. The UFT-M is designed to measure temperature fluctuations, and such drift is acceptable.

A comprehensive description of accuracy, resolution and overall performance of UFT sensors can be found in Haman et al. (1997). Below we discuss in more detail errors due to radiation and velocity fluctuations. The first is estimated from the comparison of heat fluxes due to solar heating of the sensing wire $Q_{r}$ and heat transfer $Q$ between the air and the sensor at temperature difference $\Delta T . Q$ per unit length of the sensing wire can be estimated after chapter 2 of Sandborn (1972) from the formula:

$Q=N_{u} \kappa \pi \Delta T \approx \kappa \pi \Delta T\left(0.318+0.69 \cdot\left(\frac{u D}{v}\right)^{1 / 2}\right)$, where $N_{u}$ is the Nusselt number, $\kappa=0.025 \mathrm{Wm}^{-1} \mathrm{~K}^{-1}$ is the heat transfer coefficient for air, $u=60 \mathrm{~m} \mathrm{~s}^{-1}$ is the air velocity, $D=2.5 \times 10^{-6} \mathrm{~m}$ is wire diameter, and $v=1.5 \times 10^{-5} \mathrm{~m}^{2} \mathrm{~s}^{-1}$ is the kinematic viscosity of air. This value compared to the radiative heat flux per unit length of the wire:

$Q_{r}=S A D$,

where $S=1300 \mathrm{Wm}^{-2}$ is the maximum solar flux and $A=0.3$ is absorption coefficient for platinum, gives the maximum temperature effect of radiation $\Delta T=0.005 \mathrm{~K}$.

Temperature effects of dynamic pressure - changes of the airflow velocity - also affect temperature measurements (see e.g. Sect. 2.5.1 in Bange et al., 2013). They depend on the recovery factor of the thermometer. Estimates the UFT recovery factor by Haman et al. (1997) give a value of 0.6. This, together with the measurement speed of $55 \mathrm{~m} \mathrm{~s}^{-1}$ and fluctuations in the range of $\pm 5 \mathrm{~m} \mathrm{~s}^{-1}$ result in the shift of temperature by $\Delta T=0.2 \mathrm{~K}$ and fluctuations $\pm 0.04 \mathrm{~K}$. The value of shift is of secondary importance, since UFTs are designed to measure small-scale temperature fluctuations, not static temperature and are used together with calibrated low-frequency temperature probes (see Sect. 3.1.3).

\subsection{Mounting of the sensor}

The mounting of the UFT-M sensor must be designed separately for each type of aircraft. During the POST campaign, the UFT-M was mounted on a particularly stiff, stainlesssteel tube positioned below the nose of the CIRPAS Twin Otter (Fig. 3) and was in proximity to the following fastresponse instruments: particle volume monitor (PVM)-100 liquid water content (LWC) probe (Gerber et al., 1994), hygrometers, including the fast NCAR Lyman- $\alpha$, (Beaton and Spowart, 2012), and a 5-hole turbulence probing system in the radome. A description of the instrumentation can be found at the POST web page: http://www.eol.ucar.edu/ projects/post/. The tube was tilted back to compensate for the typical angle of attack during the measurements. Easily accessible clamps allowed for the adjustment of the support length; these adjustments helped keep the sensor outside major disturbances of the flow and minimise vibrations. The entire tube with the sensors could be replaced or repositioned in a few minutes, even during field conditions. A $1.5 \mathrm{~m}$-long, double-shielded signal cable was led along the tube. The cable was equipped with a connector that was compatible with a receptacle at the input of the analogue-to-digital converter (ADC), located in a shielded box in the baggage compartment of the aircraft.

\subsection{Data recording}

Before digitisation with 16 bit resolution, both temperature signals were conditioned using a low-pass filter of selectable limiting frequencies: $2.5,5$ and $10 \mathrm{kHz}$. At the signal input 


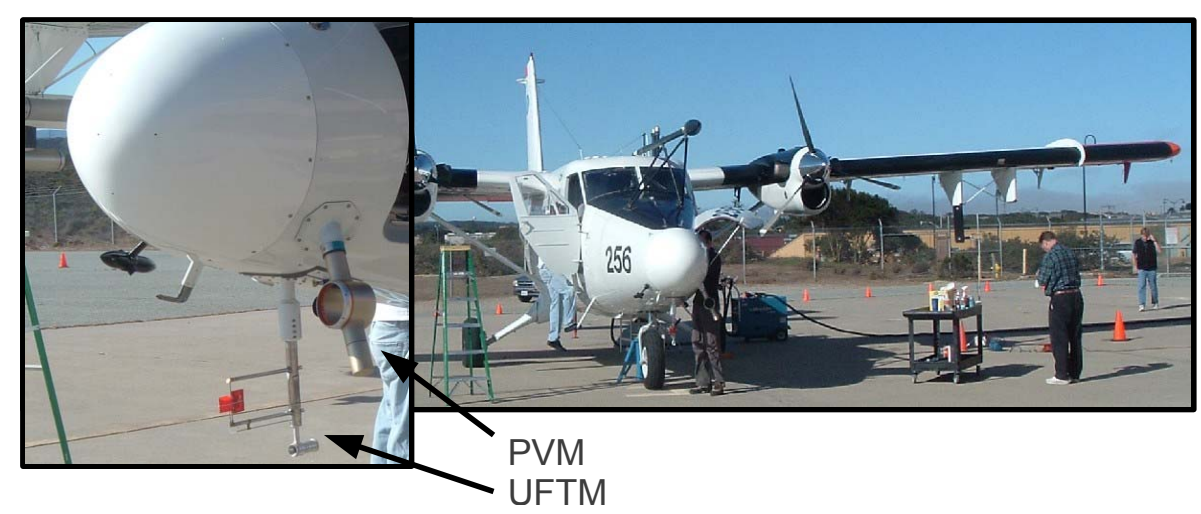

Fig. 3. UFT-M and other fast-response sensors mounted close together around the nose of the Twin Otter research aircraft during POST.

range of $\pm 5 \mathrm{~V}$, the least significant bit corresponded to $0.15 \mathrm{mV}$, i.e. $0.006 \mathrm{~K}$. A $1 \mathrm{~Hz}$ square wave analogue signal, which allowed for the synchronisation of all instruments aboard the aircraft, was connected to the third input of the ADC. The maximum theoretical sampling rate of the device was $2 \times 10^{5}$ samples per second $\left(200 \mathrm{kS} \mathrm{s}^{-1}\right)$ on all channels. In practice, to avoid data loss, three signals (two temperatures and time sync) were digitised at a rate of $2 \times 10^{4} \mathrm{~S} \mathrm{~s}^{-1}$ $\left(20 \mathrm{kS} \mathrm{s}^{-1}\right)$ in each channel. This value was set to match the minimum theoretical time constant of the sensor estimated from its length $(5 \mathrm{~mm})$ and typical true airspeed $\left(50 \mathrm{~m} \mathrm{~s}^{-1}\right)$ as $1 \times 10^{-4} \mathrm{~s}$, in agreement with previous calculations and experimental estimates (Haman et al., 1997). The limiting frequency of the low-pass conditioning filter was accordingly set to $10 \mathrm{kHz}$.

The digital signal was sent via a shielded $10 \mathrm{~m}$-long USB cable (with the signal amplifier) to the portable computer inside the cabin and recorded on a hard disk. Typically $\sim 10 \mathrm{~GB}$ of raw data were collected during each flight.

\section{Data processing and evaluation}

As a preliminary quality check following the flight, the data were visually inspected for major flaws. Such inspection after the first flight revealed artefacts in the form of a regular series of high-amplitude spikes. Ground tests have shown that despite careful shielding, one of the avionic systems was interfering with the sensor. Fortunately, the system could be switched off, except during landing procedures. Other problems, such as sensor ageing (which affected the long-term drift of the signal and led to a decrease in sensitivity) were solved by regularly replacing the sensing elements every 13 flights.

Except for quick assessments and initial quality checks, volume data processing had to be performed a posteriori. Evaluating the records revealed two major types of artefacts: (1) occasional switching between three recorded channels (two temperatures and time sync) in data streams; and
(2) separate random spikes in the signal records, indicating that not all interferences with avionics were eliminated.

\subsection{Error correction, time synchronisation, calibration and signal averaging}

\subsubsection{Error correction}

Two types of errors required different detection and correction methods. First, occasional switching between the channels was rare, relatively easy to detect and correct, except for a few cases that resulted in the loss of a small amount of data. Second, random spikes which deviated substantially from the local signal level. We tested several error-correction algorithms, e.g. based on median of absolute deviations (MAD) as in Papale et al. (2006) and Mauder et al. (2013). We found that statistics of temperature fluctuations in various segments of the record (e.g. free troposphere, temperature inversion, and cloud top region) are very different. MAD-based algorithms lead to rejection of many good and interesting data segments, even when applied to e.g. high-pass filtered data in order to remove large-scale temperature fluctuations. Finally, since spikes were typically single-point events, a simple detection algorithm produced satisfactory results: the signal value $V(n)$ at point $n$ was subtracted from the arithmetic mean $(V(n-1)+V(n+1)) / 2$ and compared to the experimentally chosen threshold $( \pm 0.15 \mathrm{~K}$, slightly above the maximum amplitude of the aerodynamic noise). When the threshold was exceeded, $V(n)$ was replaced by the arithmetic mean $(V(n-1)+V(n+1)) / 2$.

\subsubsection{Time synchronisation}

A $1 \mathrm{~Hz}$ square-wave reference timer signal from a GPS clock on the plane was used to precisely synchronise the $20 \mathrm{kS} \mathrm{s}^{-1}$ temperature records with those from other instruments. The corrected and synchronised $20 \mathrm{kS} \mathrm{s}^{-1}$ UFT-M signal was averaged, and time series of $1000,100,10$ and $1 \mathrm{~S} \mathrm{~s}^{-1}$ were produced. 


\subsubsection{Calibration and averaging}

To calibrate the temperature signal against the reference thermometer in Rosemount housing (UCI temperature probe described in Friehe and Khelif, 1992), $1 \mathrm{~S} \mathrm{~s}^{-1}$ series were used. Calibration was completed in each flight for each particular UFT-M sensor and was aimed to determine sensitivity rather than absolute accuracy. Multivariate fits, accounting for variations of the true air speed were tested, but they did not produce better results than the best linear fit. Figure 4 presents an example of calibration that illustrates the $1 \mathrm{~S} \mathrm{~s}^{-1}$ temperature from the UCI probe of one of the UFT-M temperature channels during the whole flight and the fit, i.e. $T=(44.302 \pm 0.003) V-(79.488 \pm 0.006)$. The slope of the fit indicates that the sensitivity of the sensor is $23 \mathrm{mV} \mathrm{K}^{-1}$, which is in reasonable agreement with theoretical estimates.

Figure 5 presents $1 \mathrm{~S} \mathrm{~s}^{-1}$ temperature records from two UFT-M sensors and the UCI probe. Clearly, a UCI signal averaged to $1 \mathrm{~S} \mathrm{~s}^{-1}$ lags behind the UFT-M signal presented according to the average readings, at least in regions of fast temperature variations. The lag in regions of large temperature jumps resulted in remarkable differences in temperature readings from both instruments, which explains the spread of calibration points observed in Fig. 4.

Figure 6 illustrates the difference in the performance of the UCI probe in the Rosemount housing and the UFT-M in more detail. Two successive panels present an example of $40 \mathrm{~S} \mathrm{~s}^{-1}$ records (maximum available resolution of UCI probe) during two stratocumulus top penetrations (descent and ascent). The LWC record from Gerber's PVM-100 shows the precise position of cloudy and clear air filaments. At $55 \mathrm{~m} \mathrm{~s}^{-1}$ true air speed, the $40 \mathrm{~S} \mathrm{~s}^{-1}$ data correspond to an approximate $1.4 \mathrm{~m}$ spatial resolution (i.e. records from all three sensors are representative of the same sampling volume). Similar to the $1 \mathrm{~S} \mathrm{~s}^{-1}$ record, the UCI temperature lags behind UFT-M. The temperature fluctuations of the UCI record are smoother than those of the UFT-M. The lag is most likely due to the thermal inertia of the Rosemount housing (Friehe and Khelif, 1992) and the heat conduction from the supports of the sensing element in the UCI probe (Payne et al., 1994). Additionally, the effects of positioning the Rosemount housing relatively close to the airplane fuselage, which gives off large thermal inertia, cannot be excluded. The maximum differences between the UFT-M and UCI probes are $0.6 \mathrm{~K}$ in the descending and $1 \mathrm{~K}$ in the ascending part of the porpoise. These values seem large, but similar differences between a UCI sensor in Rosemount housing and a NCAR K-probe in flight through inversions have been reported (Friehe and Khelif, 1992). Additionally, another previous study (Cruette et al., 2000) presented data indicating similar differences between the recorded temperature values and the lag of the Rosemount temperature behind a fast-response airborne ultrasonic thermo-anemometer.

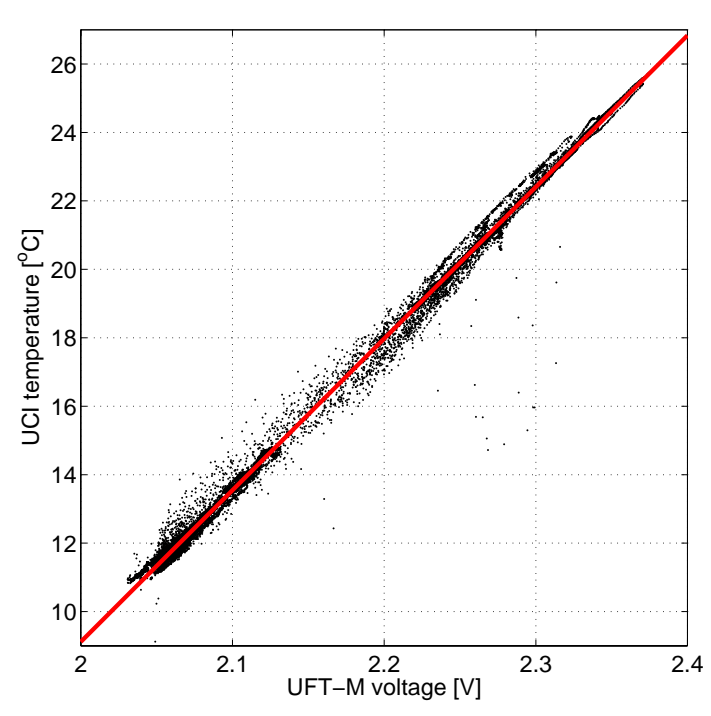

Fig. 4. Example calibration of the UFT-M1 (one sensor) against a $1 \mathrm{~S} \mathrm{~s}^{-1}$ record from the University of California temperature sensor in Rosemount housing. Each dot corresponds to a $1 \mathrm{~s}$ average from the UFT-M1.

Wetting of either thermometer should result in a temperature drop at the exit from the cloud into clear unsaturated air (cf. Figs. 9, 11, 12, and 14 in Lawson and Cooper, 1990, Fig. 4 in Haman et al., 2001, and discussion in Wang and Geerts, 2009). No similar patterns were detected, but low LWC in the investigated clouds and a high-temperature difference between the cloud and the free troposphere could mask the signatures of UFT-M wetting. There is, however, an indirect signature of Rosemount housing wetting: differences in temperature records between the UFT-M and the UCI sensor are usually larger at the cloud exit (ascending part of the porpoise) than at the cloud entrance (penetration into the cloud).

Data sets and metadata after error correction, calibration, visual signal inspection and comparison of the two UFT$\mathrm{M}$ temperature sensors have been uploaded to the POST database. Raw, error-corrected and calibrated $20 \mathrm{kS} \mathrm{s}^{-1}$ data can be obtained from the authors.

\subsection{Performance of the UFT-M}

The UFT-M has been thoroughly tested in typical flight conditions with respect to signal quality, frequency response and the compatibility of both sensing elements. The UFT$\mathrm{M}$ frequency response is clearly illustrated by an example of the power spectral density (PSD) of the temperature fluctuations recorded in the turbulent inversion above the cloud top, as shown in the upper panel in Fig. 7. The following PSDs are plotted: the calibrated $20 \mathrm{kS} \mathrm{s}^{-1}$ signal after adapting the spike removal procedure (red), the same signal filtered digitally with a 20th order low-pass Butterworth filter of $2.5 \mathrm{kHz}$ cutoff frequency and no phase shift (blue) and, 
$1 \mathrm{~Hz}$ UFT-M and UCI Rosemount temperature records compared

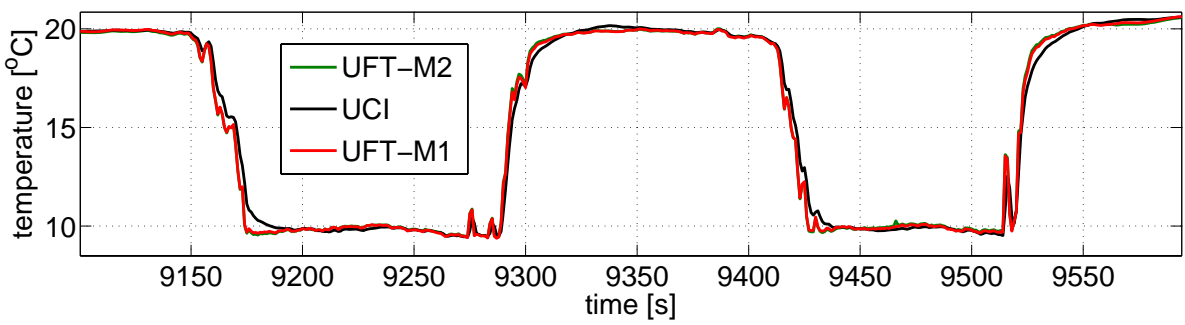

Fig. 5. Comparison of $1 \mathrm{~S} \mathrm{~s}^{-1}$ temperature records from UFT-M1, UFT-M2 and UCI in the course of two consecutive porpoises.
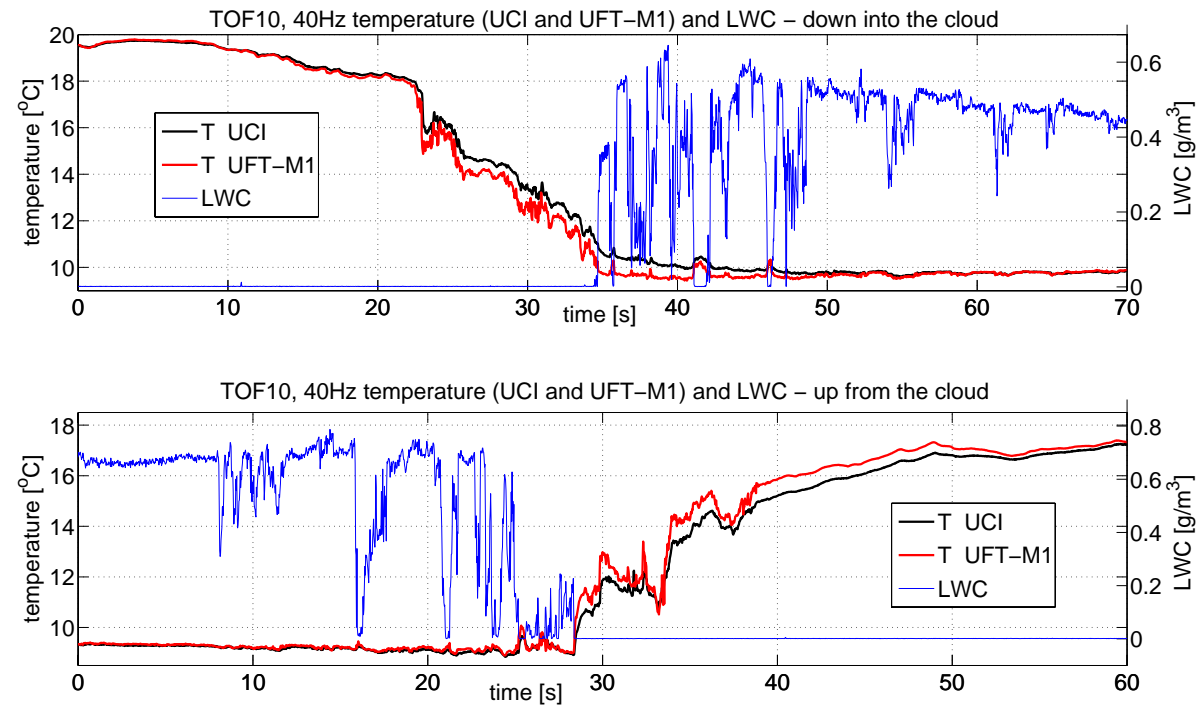

Fig. 6. Example UFT-M1 and UCI Rosemount $40 \mathrm{~S} \mathrm{~s}^{-1}$ temperature records in the course of penetrations from cloud to free atmosphere (upper panel) and from free atmosphere to cloud (lower panel). The $40 \mathrm{~S} \mathrm{~s}^{-1}$ LWC signal from PVM is added to show the cloud.

finally, the signal averaged down to $1 \mathrm{kS} \mathrm{s}^{-1}$ as submitted to the POST database (black). At frequencies up to $\sim 2 \mathrm{kHz}$ all PSDs roughly follow the $-5 / 3$ power law. All spectra overlap up to $300 \mathrm{~Hz}$. Differences above $300 \mathrm{~Hz}$ are due to averaging, which effectively dampens residual spikes. The PSDs of the filtered and the unfiltered data overlap up to $2 \mathrm{kHz}$. Above $2 \mathrm{kHz}$, vortex shedding from the rod produces temperature fluctuations (thermal noise), which add energy to the power spectrum. This is effectively filtered by the digital low-pass filter. All spectra have a visible, very narrow peak at $90 \mathrm{~Hz}$, which is the signature of the acoustic wave from the aircraft's propellers.

To illustrate the effect of residual spikes and temperature fluctuations (thermal noise) in the wake of the rod, the lower panel in Fig. 7 illustrates a temperature record collected in a thermally uniform free troposphere region and is presented at different stages of processing procedure. It follows that the amplitude of temperature fluctuations due to vortex shedding is $\sim 0.05 \mathrm{~K}$. Low-pass filtering and averaging effectively remove these fluctuations. Small residual spikes due to the interaction with avionics, not removed in the course of signal processing, slightly affect the filtered signal but have a minor influence on the averaged record. Thus, the plot demonstrates that the errors due to aerodynamic thermal noise and imperfect spike removal in the UFT-M data that have been averaged to the $1 \mathrm{kS} \mathrm{s}^{-1}$ are smaller than $\pm 0.05 \mathrm{~K}$ and that the similar errors on the $20 \mathrm{kS} \mathrm{s}^{-1}$ filtered data are smaller than $\pm 0.1 \mathrm{~K}$.

In Fig. 8, the unfiltered (red), filtered (blue) and $1000 \mathrm{~S} \mathrm{~s}^{-1}$ averaged signals (black) from two nearby $(0.5 \mathrm{~cm}$ apart $)$ sensing wires of UFT-M are compared. The unfiltered records show that the sensing wire of UFT-M2 is affected by larger temperature fluctuations in the wake than the sensing wire of UFT-M1. These fluctuations are the result of small, unavoidable imperfections in the assembling procedure that can result from asymmetries or differences in soldering, among other factors. The discussion in Sect. 5 of Rosa et al. (2005), based on a detailed two-dimensional modelling of the flow around the protecting rod, explains the mechanisms of differences due to asymmetry in the location of sensing wires. Filtering and averaging effectively eliminates these 

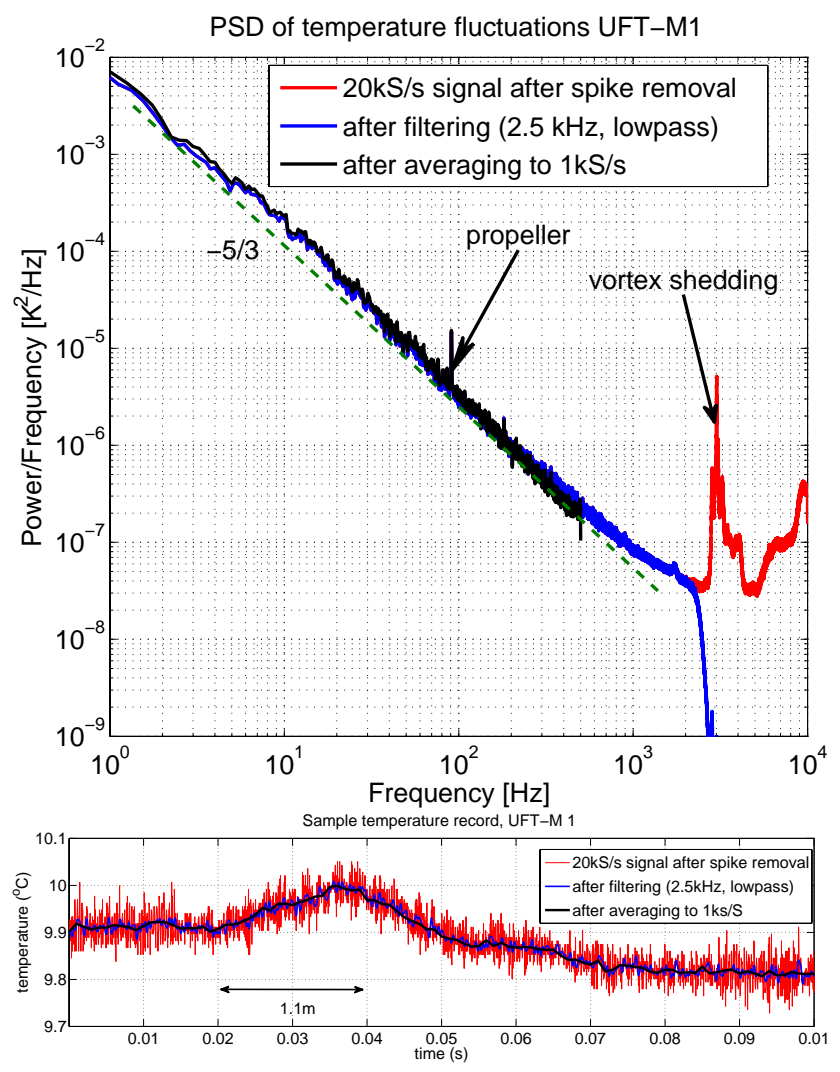

Fig. 7. Upper panel: power spectral density (PSD) of the temperature fluctuations in the entrainment interfacial layer and inside the cloud. The red line represents a PSD of the $20 \mathrm{kS} \mathrm{s}^{-1}$ temperature signal after error corrections; blue line - PSD of the same signal that was digitally filtered with a 20th order low-pass Butterworth filter of $2.5 \mathrm{kHz}$ cutoff frequency; black line - PSD of the signal averaged to $1 \mathrm{kS} \mathrm{s}^{-1}$. Lower panel: comparison of the unfiltered, filtered and averaged signal.

effects: the $1000 \mathrm{~S} \mathrm{~s}^{-1}$ averaged signals from both sensing wires differ only to a marginal degree.

Another analysis of the differences observed in the exposures of the UFT-M1 (black) and UFT-M2 (red) sensing wires to wake eddies is presented in Fig. 9. The power spectra of unfiltered temperature signals disagree at frequencies above $2 \mathrm{kHz}$.

\section{Example records}

The upper panel in Fig. 10 presents the typical temperature and LWC fluctuations averaged to a rate of $100 \mathrm{~S} \mathrm{~s}^{-1}$ while descending at a constant vertical velocity of $1.6 \mathrm{~m} \mathrm{~s}^{-1}$ from the free troposphere to the cloud deck during research flight TO10. Three regions of clearly defined characteristics of temperature fluctuations can be distinguished. In the first region, i.e. the free troposphere (time span $0-9 \mathrm{~s}$, height range 698-684 m), the temperature record is smooth, and the variations occur in the horizontal scales on the order of $100 \mathrm{~m}$

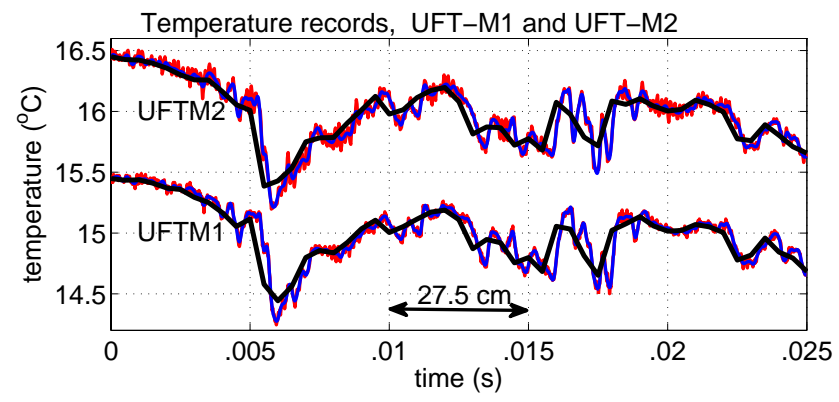

Fig. 8. Temperature fluctuations from two sensing wires of UFT-M. Temperature record from UFT-M2 was shifted up for comparison with that from UFT-M1. Colour code corresponds to that in Fig. 7.

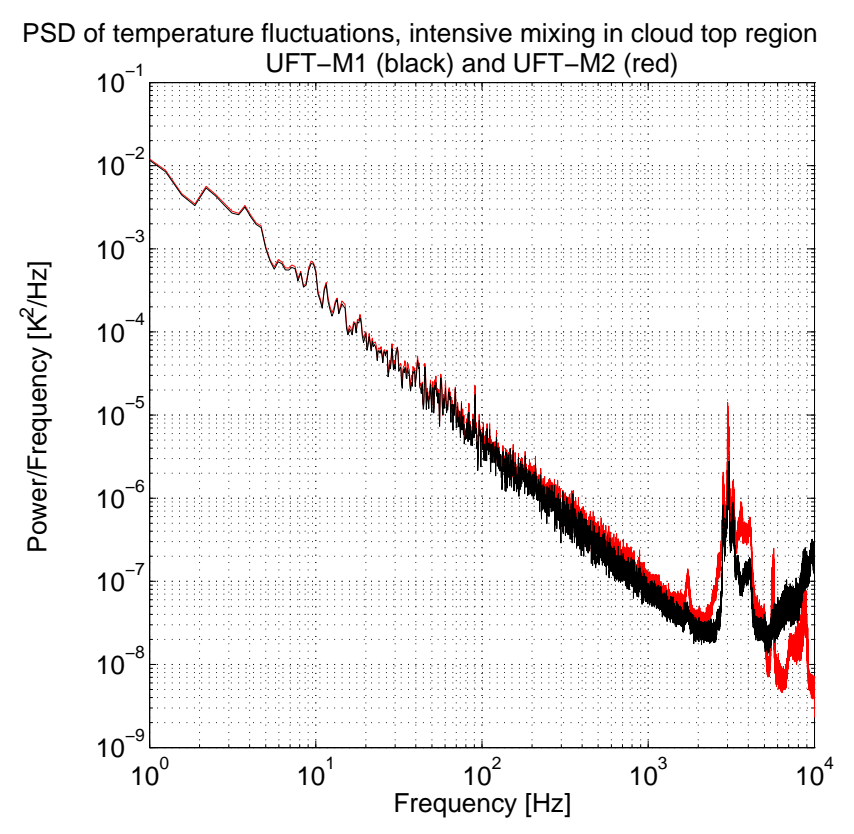

Fig. 9. Power spectra of the error corrected, unfiltered signals from two nearby sensing wires, UFT-M1 and UFT-M2, recorded in the region of intensive turbulent mixing.

or greater. The next segment of the record, which lasts until $21.2 \mathrm{~s}$ (height range $684-666 \mathrm{~m}$ ), is characterised by a systematic drop of the mean temperature, and sharp, small-scale fluctuations are superimposed. This corresponds to typical thermal characteristics of inversion capping stratocumulus. Similar properties of inversion, denoted as the entrainment interfacial layer (EIL), were observed in DYCOMS II (Dynamics and Chemistry of Marine Stratocumulus) by Gerber et al. (2005) and Haman et al. (2007). The maximum amplitude of temperature fluctuations in the layer is $\sim 2 \mathrm{~K}$, which is considerably lower than the $8 \mathrm{~K}$ temperature jump across the inversion. This suggests that turbulent eddies and mixing events in this layer have a vertical extent smaller than the thickness of EIL; otherwise, filaments with temperature differences as large as the inversion strength should be 

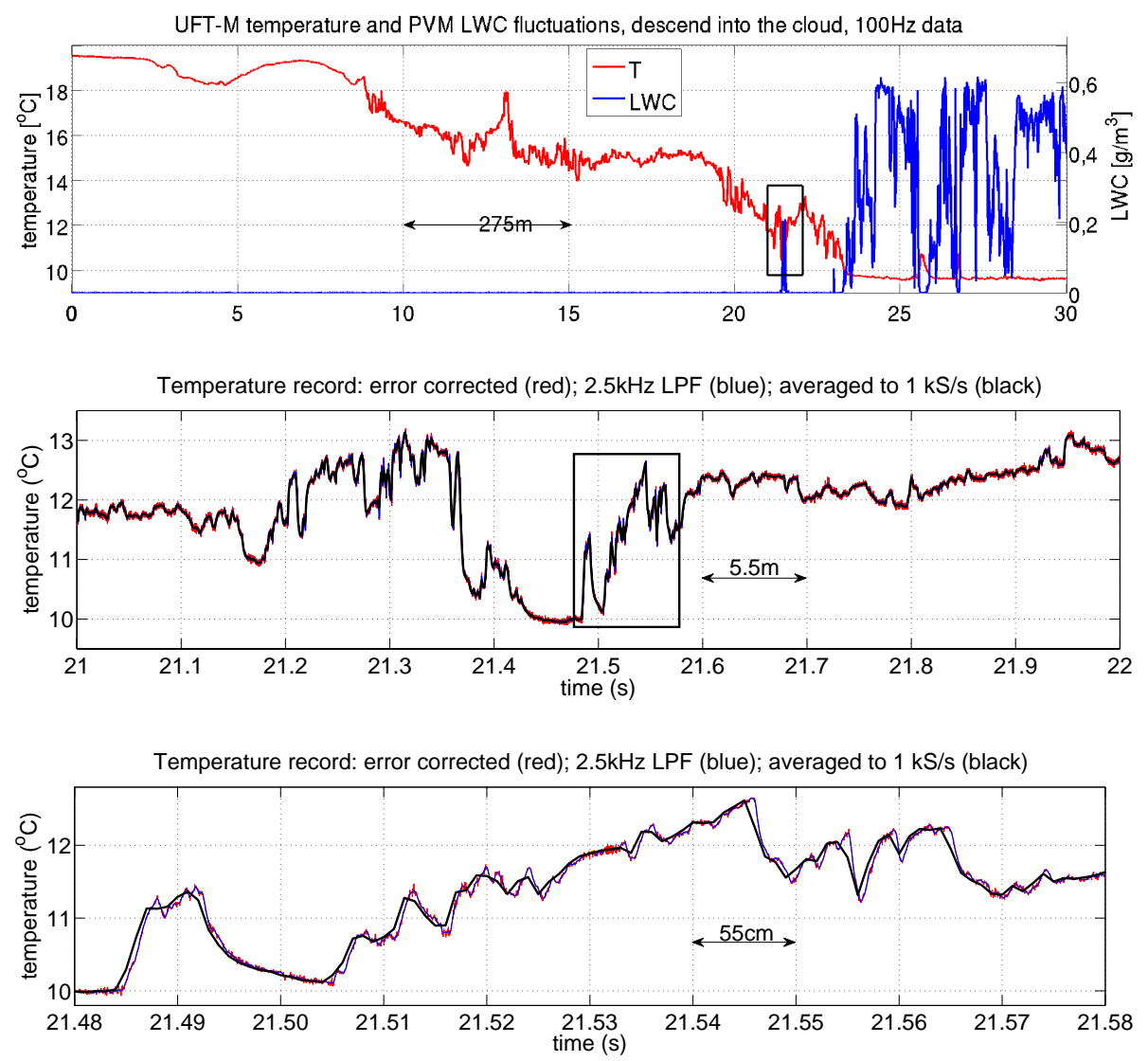

Fig. 10. The uppermost panel presents temperature fluctuations (red) recorded during the descent into the stratocumulus cloud. The smooth signal at $0-9 \mathrm{~s}$ is identified as recorded inside the free troposphere; that at 9-21.2 s as the temperature fluctuations in the inversion capping the cloud deck (no significant LWC, blue); and that at 21.2-30 s as the temperature fluctuations at the cloud top and inside the cloud. The two lower panels present consecutive blow-ups of temperature records to illustrate sensor performance. Colour code on these panels correspond to that in Fig. 7.

observed. At $21.2 \mathrm{~s}$, the LWC signal indicates that the aircraft enters the first blob of cloud, i.e. begins to penetrate the cloud's top layer. Cloudy filament is characterised by a low temperature and small temperature fluctuations. Clear air filaments exhibit increased temperatures, and the temperature differences between cloudy and clear air regions are similar to the differences observed in EIL. A comprehensive analysis of the consecutive layers in the stratocumulus' top region, distinguished based on high-resolution measurements, is presented in a recent study of Malinowski et al. (2013).

The next panels in Fig. 10 present blow-ups of the temperature patterns to illustrate the error-corrected (red), lowpass filtered (blue) and averaged (black) UFT-M records. The timescale corresponds to this scale in the upper panel. The middle panel is centred on the first cloud parcel penetrated by the aircraft (21.36-21.52 s, LWC not shown). The temperature variations indicate small-scale (thickness $10 \mathrm{~cm}$ ) filaments of different temperatures that are present on the sides of the cloud parcel. The temperature inside the cloud parcel drops to $10^{\circ} \mathrm{C}$. In the bottom panel, a filament structure on the right-hand side of the cloud parcel is shown. The temporal resolution of this image demonstrates the advantages of the UFT-M.

Due to a close collocation of the PVM and the UFT-M (separation of the instruments $\sim 45 \mathrm{~cm}$, c.f. Fig. 3 and detailed sketches in Gerber et al., 2010, 2013), the LWC and temperature signals, when averaged to $100 \mathrm{~S} \mathrm{~s}^{-1}(55 \mathrm{~cm}$ resolution), can be treated as collected in the same sampling volume. Thus, the correlations of temperature and LWC in cloudy volumes on scales larger than $\sim 0.5 \mathrm{~m}$ can be investigated. Examples of correlation studies aimed at analysing the buoyancy of cloud parcels can be found in Malinowski et al. (2011); Gerber et al. (2013).

The next demonstration of the UFT-M capabilities is given in Fig. 11, illustrating the PSDs of $1000 \mathrm{~S} \mathrm{~s}^{-1}$ temperature records (flight TO10) from selected sub-layers of the turbulent, stratocumulus-topped boundary layer. Dot-dashed lines show a reference $-5 / 3$ slope, which represents the value expected in turbulent flows with contrasts of passive scalar content (see, e.g. Warhaft, 2000). For frequencies lower than $10 \mathrm{~Hz}$ (i.e. detectable with typical aircraft temperature sensors), all spectra are parallel to the $-5 / 3$ slope, suggesting 


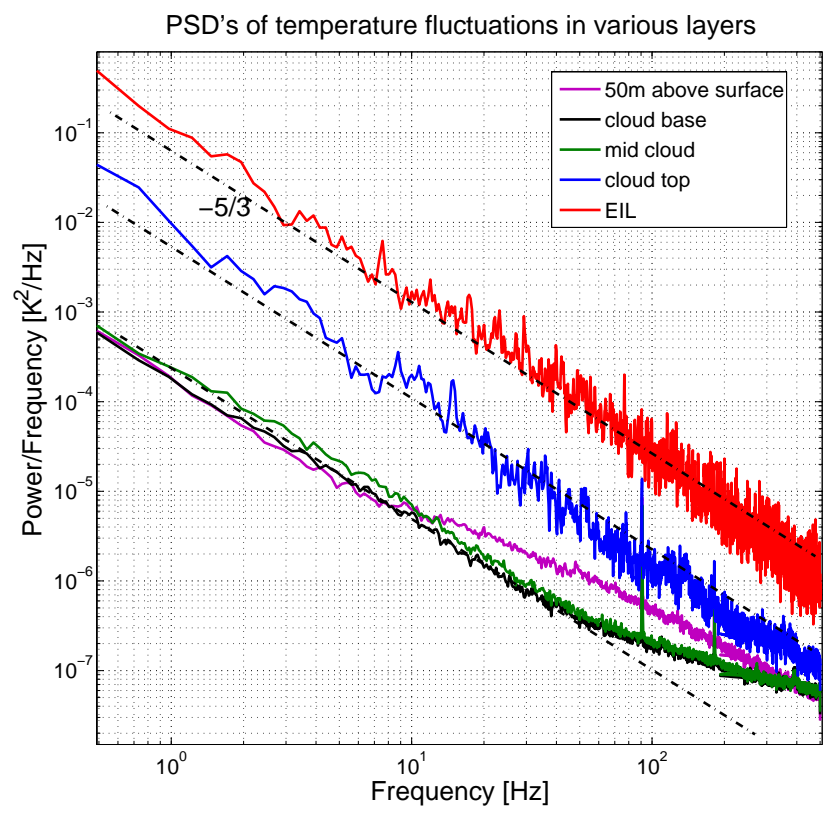

Fig. 11. Example PSDs of temperature fluctuations of a $1 \mathrm{kS} \mathrm{s}^{-1}$ signal collected at various levels of a turbulent stratocumulus topped boundary layer.

that temperature behaves in a passive scalar manner. At higher frequencies three spectra are less inclined, suggesting more temperature variance than expected. For cloud base and mid-cloud cases (green and black curves in the plot) the effect is of instrumental origin, where rounding (truncation) level $0.01 \mathrm{~K}_{\text {of }}$ the $1000 \mathrm{~S} \mathrm{~s}^{-1}$ record is reached. For the measurements $50 \mathrm{~m}$ above the sea surface (purple curve) the effect reflects real thermal properties of the flow above sea surface. While a discussion of the physical nature of this effect extends beyond the description of the UFT-M, the presented power spectra indicate the ability to investigate the scaling properties of temperature fluctuations using the fast temperature sensor, and shows that thermal resolution of $1000 \mathrm{~S} \mathrm{~s}^{-1}$ data corresponds to truncation of $0.01 \mathrm{~K}$.

\section{Conclusions}

An improved airborne ultrafast thermometer, UFT-M, which is the youngest member of the UFT family, was developed at the University of Warsaw and confirmed to be an efficient and reliable sensor. Analyses of collected data indicate that a mounted UFT-M on aircraft operating in the course of measurements with an airspeed of $\sim 55 \mathrm{~m} \mathrm{~s}^{-1}$ allows insight into the small-scale temperature structure of clouds and the atmospheric boundary layer. Unfiltered signals permit the detection of temperature jumps at distances of $\sim 1 \mathrm{~cm}$, on the condition that these jumps exceed $0.1 \mathrm{~K}$, i.e. exceeding the amplitude of the aerodynamic thermal noise resulting from the sensor construction. Digital filtering of the recorded signal with a $2.5 \mathrm{kHz}$ cutoff frequency efficiently removes the aerodynamic noise and allows investigating the temperature variations at a centimetre scale. Additional averaging to $1000 \mathrm{~S} \mathrm{~s}^{-1}$, aimed at removing some related artefacts, produces a high-quality record of temperature fluctuations in clouds with the spatial resolution of $5.5 \mathrm{~cm}$ at $55 \mathrm{~m} \mathrm{~s}^{-1}$ true airspeed of the airplane and thermal resolution of $0.01 \mathrm{~K}$. This record is not affected by the influence of housing, which, even in the presence of a relatively fastresponse sensor inside, distorts the temperature readings. Using a UFT-M in a POST field campaign on board a CIRPAS Twin Otter research aircraft provided a unique documentation of the thermal structure of stratocumulus clouds at $5.5 \mathrm{~cm}$ spatial resolution, which is available in the open database http://www.eol.ucar.edu/projects/post/. Higher resolution data on temperature fluctuations (up to $20 \mathrm{kS} \mathrm{s}^{-1}$ ) are available from the authors.

Acknowledgements. This research was supported by the National Science Foundation with the grant ATM-0735121 and by the Polish Ministry of Science and Higher Education with the matching grant 186/W-POST/2008/0. Special acknowledgements are due to Hermann Gerber for organising POST. We thank all POSTers and CIRPASers, led by Haflidi H. Jonsson, for an excellent collaboration during the field campaign. We acknowledge Imai Jen-La Plante for language corrections.

Edited by: F. X. Meixner

\section{References}

Bange, J., Esposito, M., Lenschow, D. H., Brown, P. R. A., Dreiling, V., Giez, A., Mahrt, L., Malinowski, S. P., Rodi, A. R., Shaw, R. A., Siebert, H., Smit, H., and Zöger, M.: Measurement of Aircraft State and Thermodynamic and Dynamic Variables, in: Airborne Measurements for Environmental Research: Methods and Instruments, edited by: Wendisch, M. and Brenguier, J. L., Wiley, 7-75, doi:10.1002/9783527653218.ch2, 2013.

Beaton, S. P. and Spowart, M.: UV absorption hygrometer for fastresponse airborne water vapour measurements, J. Atmos. Ocean. Tech., 29, 1295-1303, doi:10.1175/JTECH-D-11-00141.1, 2012.

Bodenschatz, E., Malinowski, S. P., Shaw, R. A., and Stratmann, F.: Can We Understand Clouds without Turbulence?, Science, 327, 970-971, doi:10.1126/science.1185138, 2010.

Carman, J. K., Rossiter, D. L., Khelif, D., Jonsson, H. H., Faloona, I. C., and Chuang, P. Y.: Observational constraints on entrainment and the entrainment interface layer in stratocumulus, Atmos. Chem. Phys., 12, 11135-11152, doi:10.5194/acp-1211135-2012, 2012.

Cruette, D., Marillier, A., Dufresne, J. L., Grandpeix, J. Y., Nacass, P., and Bellec, H.: Fast Temperature and True Airspeed Measurements with the Airborne Ultrasonic Anemometer Thermometer (AUSAT), J. Atmos. Ocean. Tech., 17, 1020-1039, doi:10.1175/1520-0426(2000)017<1020:FTATAM > 2.0.CO;2, 2000 . 
Devenish, B. J., Bartello, P., Brenguier, J.-L., Collins, L. R., Grabowski, W. W., Ijzermans, R. H. A., Malinowski, S. P., Reeks, M. W., Vassilicos, J. C., Wang, L.-P., and Warhaft, Z.: Droplet growth in warm turbulent clouds, Q. J. Roy. Meteorol. Soc., 138, 1401-1429, doi:10.1002/qj.1897, 2012.

Eastin, M. D., Black, P. G., and Gray, W. M.: Flight-Level Thermodynamic Instrument Wetting Errors in Hurricanes, Part I: Observations, Mon. Weather Rev., 130, 825-841, doi:10.1175/15200493(2002)130<0825:FLTIWE > 2.0.CO;2, 2002.

Friehe, C. A. and Khelif, D.: Fast response aircraft temperature sensors, J. Atmos. Ocean. Tech., 9, 784-795, doi:10.1175/15200426(1992)009<0784:FRATS > 2.0.CO;2, 1992.

Gerber, H., Arends, B. G., and Ackerman, A. S.: A new microphysics sensor for aircraft use, Atmos. Res., 31, 235-252, doi:10.1016/0169-8095(94)90001-9, 1994.

Gerber, H., Frick, G., Malinowski, S. P., Brenguier, J.-L., and Burnet, F.: Holes ans entrainment in stratocumulus, J. Atmos. Sci., 62, 443-459, doi:10.1175/JAS-3399.1, 2005.

Gerber, H., Frick, G., Malinowski, S. P., Kumala, W., and Krueger, S.: POST - A New Look at stratocumulus, 13th AMS Conference on Cloud Physics, 28 June-2 July 2010, 10.1, available at: https://ams.confex.com/ams/pdfpapers/170431.pdf, last access: 27 June 2013, Portland, OR, USA, 2010.

Gerber, H., Frick, G., Malinowski, S. P., Jonsson, H., Khelif, D., and Krueger, S.: Entrainment in Unbroken stratocumulus, J. Geophys. Res., submitted, 2013.

Haman, K. E.: A new thermometric instrument for airborne measurements in clouds, J. Atmos. Ocean. Tech., 9, 86-90, doi:10.1175/1520-0426(1992)009<0086:ANTIFA > 2.0.CO;2, 1992.

Haman, K. E. and Malinowski, S. P.: Temperature measurements in clouds on a centimeter scale - Preliminary results, Atmos. Res., 41, 161-175, doi:10.1016/0169-8095(96)00007-5, 1996.

Haman, K. E., Makulski, A., Malinowski, S. P., and Busen, R.: A new ultrafast thermometer for airborne measurements in clouds, J. Atmos. Ocean. Tech., 14, 217-227, doi:10.1175/15200426(1997)014<0217:ANUTFA > 2.0.CO;2, 1997.

Haman, K. E., Malinowski, S. P., Strus, B. D., Busen, R., and Stefko, A.: Two new types of ultra-fast aircraft thermometer, J. Atmos. Ocean. Tech., 18, 117-134, doi:10.1175/15200426(2001)018<0117:TNTOUA > 2.0.CO;2, 2001.

Haman, K. E., Malinowski, S. P., Kurowski, M. J., Gerber, H., and Brenguier, J.-L.: Small-scale mixing processes at the top of a marine stratocumulus - A case study, Q. J. Roy. Meteorol. Soc., 133, 213-226, doi:10.1002/qj.5, 2007.

Inverarity, G. W.: Correcting Airborne Temperature Data for Lags Introduced by Instruments with Two-Time-Constant Responses, J. Atmos. Ocean. Tech., 17, 176-184, doi:10.1175/15200426(2000)017<0176:CATDFL>2.0.CO;2, 2000.

Lawson, R. P. and Cooper, W. A.: Performance of some airborne thermometers in clouds, J. Atmos. Ocean. Tech., 7, 480-494, doi:10.1175/1520-0426(1990)007<0480:POSATI>2.0.CO;2, 1990.

Malinowski, S. P. and Leclerc, M. Y.: Fractal properties of temperature fluctuations in the convective surface layer, Bound.-Lay. Meteorol., 71, 169-187, doi:10.1007/BF00709225, 1994.

Malinowski, S. P., Andrejczuk, M., Grabowski, W. W., Korczyk, P., Kowalewski, T. A., and Smolarkiewicz, P. K.: Laboratory and modelling studies of cloud-clear air interfacial mixing: anisotropy of small-scale turbulence due to evaporative cooling, New J. Phys.,10, 075020, doi:10.1088/1367-2630/10/7/075020, 2008.

Malinowski, S. P., Haman, K. E., Kopec, M. K., Kumala, W., and Gerber, H.: Small-scale turbulent mixing at stratocumulus top observed by means of high resolution airborne temperature and LWC measurements, J. Phys. Conf. Ser., 318, 072013, doi:10.1088/1742-6596/318/7/072013, 2011.

Malinowski, S. P., Gerber, H., Jen-La Plante, I., Kopec, M. K., Kumala, W., Nurowska, K., Chuang, P. Y., Khelif, D., and Haman, K. E.: Physics of Stratocumulus Top (POST): turbulent mixing across capping inversion, Atmos. Chem. Phys. Discuss., 13, 15233-15269, doi:10.5194/acpd-13-15233-2013, 2013.

Mauder, M., Cuntz, M., Drüe, C., Graf, A., Rebmann, C., Schmid, H. P., Schmidt, M., and Steinbrecher, R.: A strategy for quality and uncertainty assessment of long-term eddycovariance measurements, Agr. Forest Meteorol., 169, 122-135, doi:10.1016/j.agrformet.2012.09.006, 2013.

Mayer, J.-C., Hens, K., Rummel, U., Meixner, F. X., and Foken, T.: Moving measurements platforms - specific and corrections, Meteorol. Z., 18, 477-488, doi:10.1127/0941-2948/2009/0401, 2009.

Metzger, S., Junkermann, W., Mauder, M., Beyrich, F., ButterbachBahl, K., Schmid, H. P., and Foken, T.: Eddy-covariance flux measurements with a weight-shift microlight aircraft, Atmos. Meas. Tech., 5, 1699-1717, doi:10.5194/amt-5-1699-2012, 2012.

Papale, D., Reichstein, M., Aubinet, M., Canfora, E., Bernhofer, C., Kutsch, W., Longdoz, B., Rambal, S., Valentini, R., Vesala, T., and Yakir, D.: Towards a standardized processing of Net Ecosystem Exchange measured with eddy covariance technique: algorithms and uncertainty estimation, Biogeosciences, 3, 571-583, doi:10.5194/bg-3-571-2006, 2006.

Payne, G. A., Friehe, C. A., and Edwards, D. K.: Time and Frequency Response of a Resistance-Wire Aircraft Atmospheric Temperature Sensor, J. Atmos. Ocean. Tech., 11, 463-475, doi:10.1175/1520-0426(1994)011<0463:TAFROA > 2.0.CO;2, 1994.

Rosa, B., Bajer, K., Haman, K. E., and Szoplik, T.: Theoretical and Experimental Characterization of the Ultrafast Aircraft Thermometer: Reduction of Aerodynamic Disturbances and Signal Processing, J. Atmos. Ocean. Tech., 22, 988-1003, doi:10.1175/JTECH1746.1, 2005.

Sandborn, V. A.: Resistance temperature transducers, Meteorology Press, Fort Collins, Colorado, 1972.

Siebert, H., Wendisch, M., Conrath, T., Teichmann, U., and Heintzberg, J.: A new balloon-borne payload for fine scale observations in the cloudy boundary layer, Bound.-Lay. Meteorol., 106, 461-482, doi:10.1023/A:1021242305810, 2003.

Siebert, H., Gerashchenko, S., Gylfason, A., Lehmann, K., Collins, L. R., Shaw, R. A., and Warhaft, Z.: Towards understanding the role of turbulence on droplets in clouds: In situ and laboratory measurements, Atmos. Res., 97, 426-437, doi:10.1016/j.atmosres.2010.05.007, 2010.

Sinkevich, A. A. and Lawson, R. P.: A Survey of Temperature Measurements in Convective Clouds, J. Appl. Meteorol., 44, 11331145, doi:10.1175/JAM2247.1, 2005. 
Wang, Y. and Geerts, B.: Estimating the Evaporative Cooling Bias of an Airborne Reverse Flow Thermometer, J. Atmos. Ocean. Tech., 26, 3-21, doi:10.1175/2008JTECHA1127.1, 2009.
Warhaft, Z.: Passive Scalars in Turbulent Flows, Annu. Rev. Fluid. Mech., 32, 203-240, doi:10.1146/annurev.fluid.32.1.203, 2000.

Wood, R.: Stratocumulus clouds, Mon. Weather Rev., 140, 23732423, doi:10.1175/MWR-D-11-00121.1, 2012. 